\title{
Stages of Oral Cancers Images Associated with Tobacco and Other Social Behaviours among Patients in Banglore State, India
}

\author{
Prerna Thaker ${ }^{1,2}$, Peter Asaga Mac ${ }^{1,3^{*}}$ and Ravi Rao $\mathrm{J}^{2}$ \\ ${ }^{1}$ Centre for Medicine and Society (Global Urban Health), University of Freiburg, Germany \\ ${ }^{2}$ Banglore Institute of Dental Science and Hospital, Bengaluru, Karnataka, India \\ ${ }^{3}$ Institute of Human Virology, University Medical Centre, Freiburg, Germany
}

*Corresponding author: Peter Asaga Mac, MD/PhD, Institute of Human virology, University of Freiburg, HermannHerder-Str 11, 79104 Freiburg, Germany

\section{Introduction}

Cancer has slowly but steadily become one of the most common causes of morbidity and mortality today [1]. World over the burden of cancer is distributed unequally between developed and developing countries with cancer types exhibiting different patterns of distribution. In India the five most frequent cancers were cancer of the lung, lip and oral cavity, other pharynx, esophagus and stomach [2].

The incidence of oral cancer in India is about 3-7 times more common as compared to other developed nations of the world [3]. In India, Southern India presents the highest oral cancer incidence rates among women worldwide, and the highest in India [1,4]. The established risk factors for oral cancer are tobacco, excessive alcohol intake, betel quid, a diet poor in fruit consumption and immune-suppression [5]. It is estimated that around $43 \%$ of cancer deaths are due to tobacco use, unhealthy diets, alcohol consumption, inactive lifestyles and infection. Other risk factors reported to be closely associated with oral cancers include poor oral health, and human papilloma virus infection. There is dearth of research in Tumors, Nodules and Metastasis (TMN) stage of the patients reporting with oral cancer widely leaving a research gap. Diagnostic delay in oral cancer may be associated with poor prognosis. There is limited knowledge on the effects and interventions aimed at reducing the delays.

\section{TNM Staging System}

TNM stands Tumour, Nodules and Matastasis. The framework depicts the measure of the introductory cancer (Essential tumour), whether the cancer has spread to the lymph nodes and whether it has spread to a distinctive portion of the body (Metastasized). The framework employed letters and numbers to depict the cancer (Figure 1, Figure 2 and Figure 3).

$\mathrm{T}$ allude to the measure of the cancer and how distant it has spread into adjacent tissue [it is number $1,2,3,4]$ with 1 being small and 4 expansive.

$\mathrm{N}$ allude to whether the cancer has spread to the lymph nodes. It can be between 0 (no lymph containing cancer cells) and 3 (part of lymph nodes containing cancer cells).

$M$ allude to whether the cancer has spread to another portion of the body. It can either be 0 (the cancer has not spread) or 1 (the cancer has spread).

\section{Conflict of Interest}

No conflict of Interest.

No support.

Citation: Thaker P, Mac PA, Ravi RJ (2019) Stages of Oral Cancers Images Associated with Tobacco and Other Social Behaviours among Patients in Banglore State, India. Clin Med Img Lib 5:129. doi. org/10.23937/2474-3682/1510129

Accepted: February 25, 2019; Published: February 27, 2019

Copyright: (C) 2019 Thaker $\mathrm{P}$, et al. This is an open-access content distributed under the terms of the Creative Commons Attribution License, which permits unrestricted use, distribution, and reproduction in any medium, provided the original author and source are credited. 


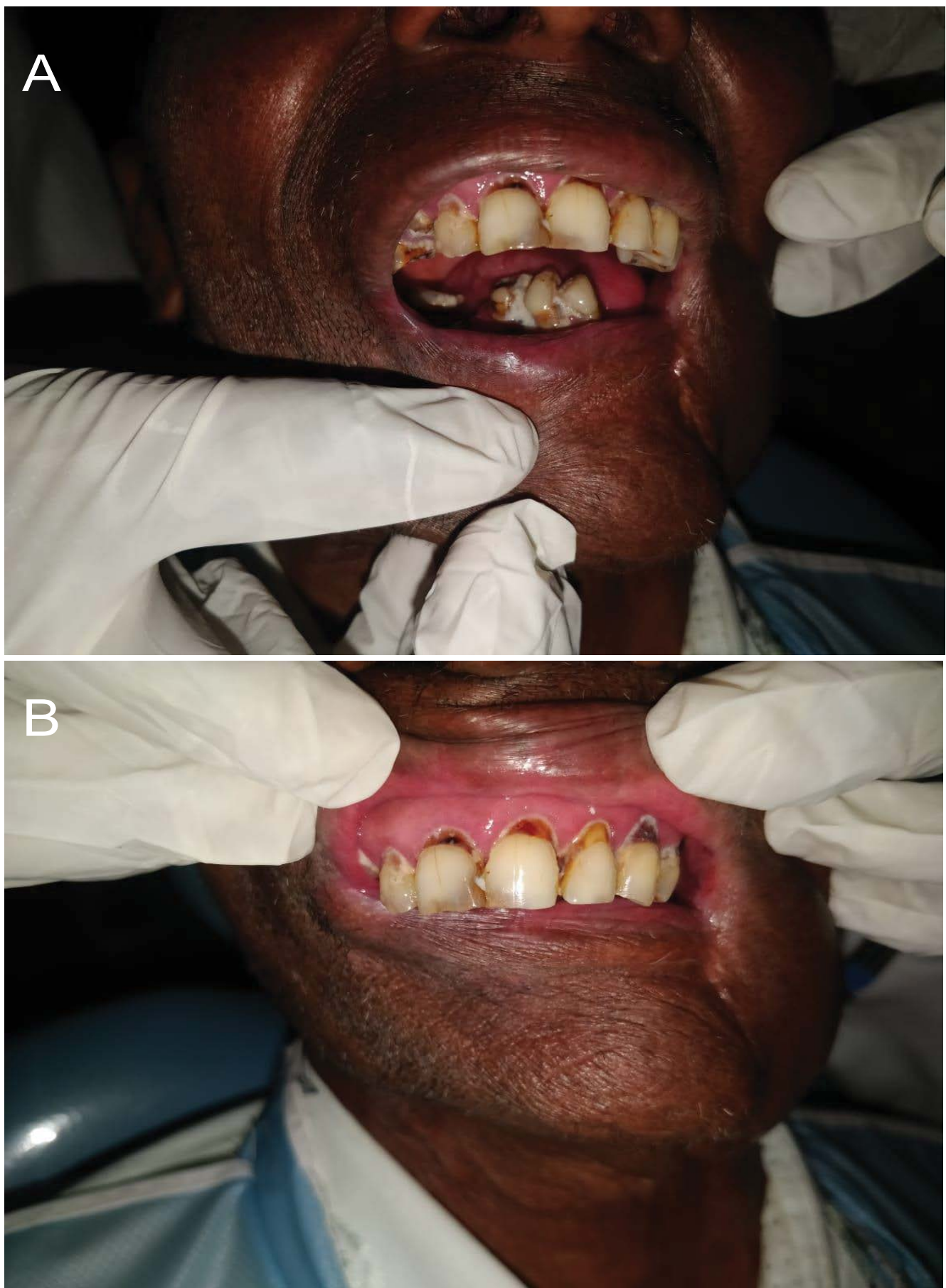

Figure 1: A) Shows oral cancer $\left(\mathrm{T}_{4 a} \mathrm{~N}_{1} \mathrm{M}_{0}\right)$ along with trismus. The tumour has invaded the anterior aspect (Between teeth number 41-32) of the mandibular bone on one side extending upto the left corner of the mouth involving the lower anterior labial sulcus and inferior labial sulcus. A single lipsilateral submental node is involved Facial; B) Shows stage T2 of oral cancer $\left(\mathrm{T}_{2} \mathrm{~N}_{1} \mathrm{M}_{0}\right)$. The tumour extends from tooth number 13 to 24 . The teeth also show cervical abrasion. Nodal involvement is as above. 

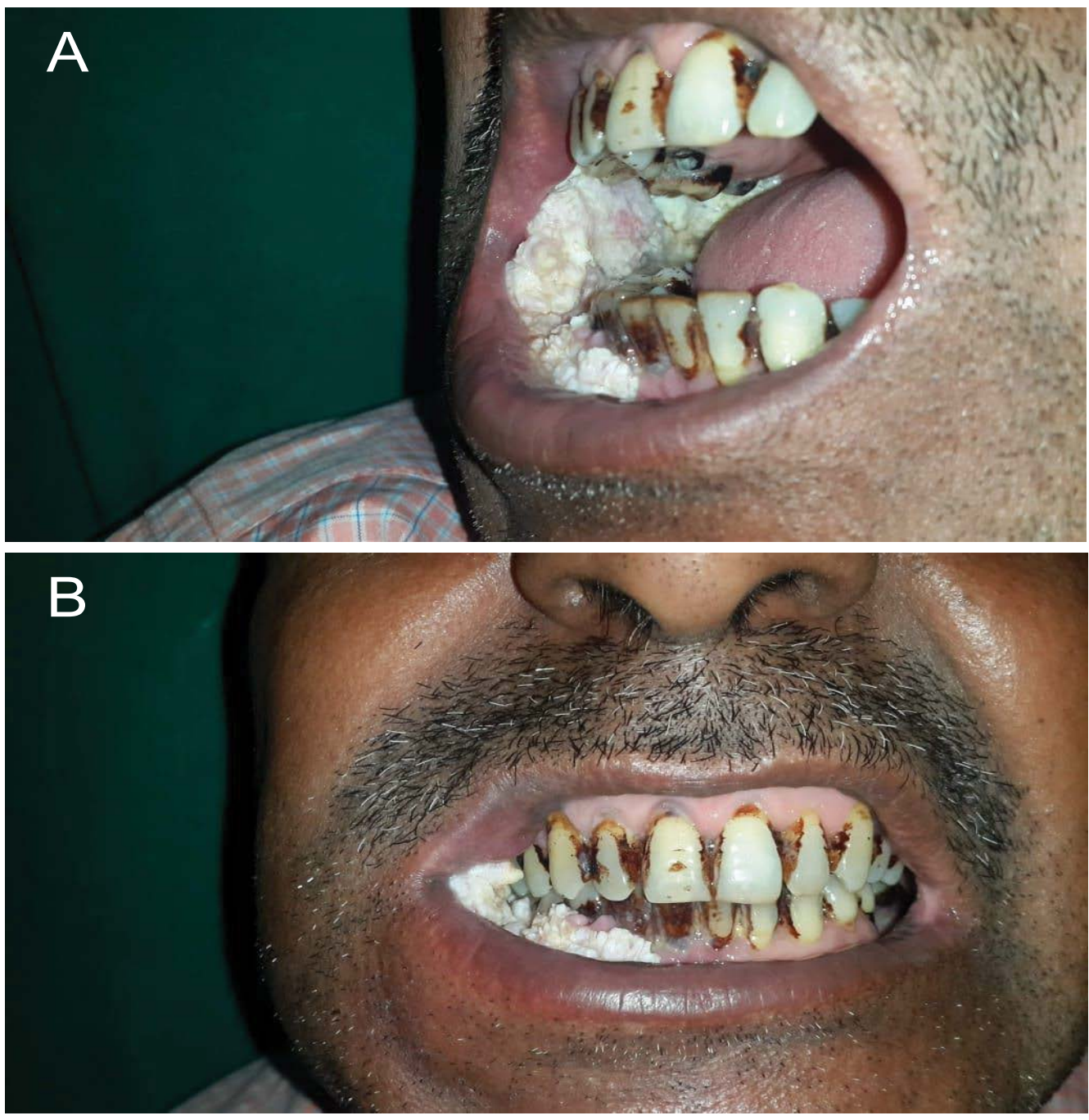

Figure 2: A) Shows stage $\mathrm{N} 3$ of oral cancer $\left(\mathrm{T}_{3} \mathrm{~N}_{3} \mathrm{M}\right)$. The tumour extends on the whole lower right quadrant of the oral cavity covering the labial sulcus and extending towards the adjacent buccal mucosa. Both the sub-mental and submandibular lymph nodes are involved. 

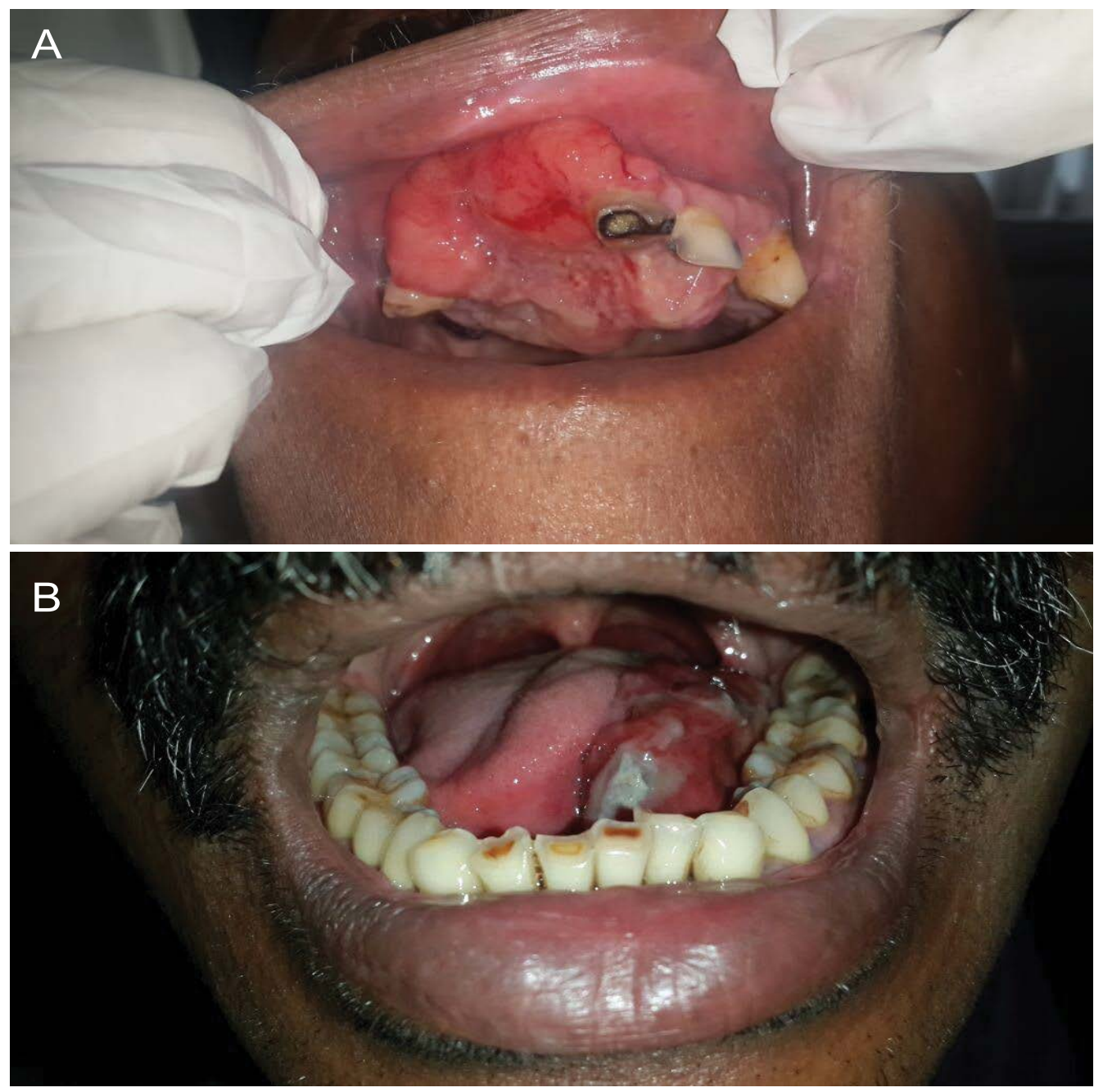

Figure 3: A) Shows stage $\mathrm{T} 3$ of oral cancer $\left(\mathrm{T}_{3} \mathrm{~N}_{1} \mathrm{M}_{0}\right)$. The tumour extends from the maxillary alveolar processes to the posterior palatine processes; B) Shows stage $T 3$ of oral cancer $\left(T_{3} N_{1} M_{0}\right)$. The tumour is evident in the left lingual sulcus extending between teeth number 38-32 involving the left dorsum of the tongue. The left submandibular nodes are affected.

\section{References}

1. Petersen PE (2099) Oral cancer prevention and control-the approach of the World Health Organization. Oral Oncol 45: $454-460$.

2. Park K (2015) Park's textbook of preventive and social medicine. (22 ${ }^{\text {nd }}$ edn), Banarsidas Bhanot Publishers.

3. Khan Z (2012) An overview of oral cancer in indian subcontinent and recommendations to decrease its incidence. WebmedCentral 3: 1-29.
4. Lizzy S, Yeole BB, Hakama M, Shiri R, Sastry PSRK, et al. (2004) Oral cancers in Mumbai, India: A fifteen years perspective with respect to incidence trend and cumulative risk. Asian Pac J Cancer Prev 5: 294-300.

5. Jayapriyaa RS, Athanasios I Zavras, Bernard Rosner, Edward Giovannucci (2010) Alcohol-folate interactions in women's oral cancer risk: A prospective cohort study. Cancer Epidemiol Biomarkers Prev 19: 2516-2524. 